\title{
USING AN ENHANCED CONFLICT MAP IN THE CLASSROOM (PHOTOELECTRIC EFFECT) BASED ON LAKATOSIAN HEURISTIC PRINCIPLE STRATEGIES
}

\author{
Received: 17 November 2009; Accepted: 21 September 2010
}

\begin{abstract}
Researchers have shown that most students resist changes to their core beliefs by offering auxiliary hypotheses at the first sign of the development of conceptual change. Studies have viewed student reaction to discrepant events as an important clue in helping researchers understand not only the structure of alternative concepts (Niaz, Science \& Education, 7(2):107 - 127, 1998) but also the nature of scientific concepts. The main objectives of this research were the following: (a) to consider prudently the conflict map of Tsai (International Journal of Science Education, 22(3):285 - 302, 2000); (b) to initiate and develop an enhanced conflict map based on Lakatosian ethodology, which could help science teachers and students resolve conflicts that occur in the explanation of natural phenomena; (c) to examine the effectiveness of the enhanced conflict map; and (d) to discuss these implications in science education. Specifically, this study used two freshman classes from the Department of Electronics and one class of Astronomy majors from C. National University, South Korea, to investigate how scientific concepts change after selecting the modern physics field (Photoelectric effect), which is included in the Physics and Astronomy courses. Modern physics has led to the so-called Lakatosian heuristic principle or methodology, a useful framework that includes scientific philosophy and science history as study strategies. "Enhanced conflict maps" are suggested for use to consistently show all the study processes.
\end{abstract}

KEY WORDS: alternative conceptions, conceptual change, Lakatosian frameworks, photoelectric effect

\section{INTRODUCTION}

A number of studies have suggested an analogy between scientists' theory development and an individual's acquisition of knowledge (Duschl \& Gitomer, 1991; Kitchener, 1987; Piaget \& Garcia, 1989; von Glasersfeld, 1989; Blanco \& Niaz, 1998). Lakatosian research program theory (Chalmers, 1982) is a current idea in science philosophy that accepts the assertions of Kuhn, who saw scientific theories as structures, but did not view scientific development as inductivism or "falsificationism." Kuhn's research program looked at scientific theories as structures that become guidelines for future studies; an example of this is the theory of Copernicus. In other words, when teachers teach scientific subjects to

International Journal of Science and Mathematics Education (2011) 9: 1135-1166

(C) The Author(s) (2010). This article is published with open access at Springerlink.com 
students, they should respect the existing regulation theories first and then emphasize new facts that have been discovered.

The popular model for conceptual changes was suggested by Posner, Strike, Hewson \& Gertzog (1982) who accepted the viewpoints of Kuhn, Lakatos, and Toulmin. This standardized individual change model sees genetic changes as analogous to the way scientific paradigms change, as suggested by science philosophers in individual studies.

Hashweh (1986) thought that the model for conceptual changes by Posner et al. (1982) was problematic in that it did not emphasize the discrimination between psychological processes and outside conditions. Hashweh also utilized Piaget's concept of cognitive disequilibrium and suggested two types of cognitive conflicts: the first type is the conflict between students' preconceptions and the present situation and the second type is the conflict between preconceptions and scientific concepts. He stressed that students' conceptions originate in their interaction with nature, and because these concepts take on a form of procedural knowledge that is continually used (automatically or subconsciously) in daily life, they do not change easily. In addition to the conflict between cognitive structure and environments, the conflict between two types of cognitive structures was emphasized.

Students' conceptions often become obstinate and resistant to change (Clement, 1982). According to the theory of constructivism, students form conceptions based on experiences obtained in daily life prior to learning in school (Driver, Guesne \& Tiberghien, 1985; West \& Pines, 1985; Hashweh, 1986). It is therefore necessary to identify students' prior conceptions and to search for teaching and learning methods that will develop these conceptions into scientific concepts.

Many studies view cognitive conflicts as important elements in conceptual change (Strike \& Posner, 1992). In other words, in order to correct students' incorrect prior concepts, it is first necessary for teachers to understand students' concepts and then suggest phenomena or materials that contradict these thoughts. However, even when teachers show contradictory examples and discordant materials, students' concepts do not change most of the time (Chinn \& Brewer, 1993, 1998; Park \& Kim, 1998; Shepardson \& Moje, 1999). According to Chin \& Brewer (1993), many psychological and educational studies provide evidence that nonscientist adults and children frequently respond to anomalous data by making these peripheral to their preexisting theories (Brewer \& Chinn, 1991; Dunbar, 1989; Heller \& Finley, 1992). Linn (1986) stated that a students' comprehension consists of the core idea that opposes changes and the insignificant idea that is subject to change from new materials or 
information. Students assert that a core idea is valid for their understanding and that it offers a framework to interpret and evaluate abnormal information and new materials.

\section{Research Purpose}

The purpose of this study was to offer teaching strategies and their corresponding instructional sequences, on the basis of Lakatosian methodology, to achieve the goal of changing students' alternative conceptions into scientific concepts.

This research is conducted to: (a) consider in depth the conflict map of Tsai (2000); (b) initiate and develop an enhanced conflict map, based on Lakatosian methodology, which could help science teachers and students resolve various conflicts that occur in the explanation of natural phenomena; (c) examine the effectiveness of the enhanced conflict map; and (d) discuss the implications for science education.

Specifically, the study aims to investigate the following research questions:

(a) Why should Lakatosian ethodology be applied to the conflict map suggested by Tsai (2000) on the basis of constructivism?

(b) How can Tsai's conflict map be enhanced and developed into a new conflict map based on Lakatosian ethodology?

(c) How can we apply this enhanced conflict map to the photoelectric effect in the university classroom?

(d) How can we analyze the application effects of the enhanced conflict map suggested by this research and what are its implications for science education?

\section{Why Should Lakatosian Methodology be Applied to the Conflict Map Suggested by Tsai (2000) on the Basis of Constructivism?}

Tsai (2000) suggested using the conflict map to deal with students' alternative conceptions based on the theoretical framework of constructivism. The first part of this study introduces the conflict map suggested by Tsai and explains why it needs to be enhanced. Tsai (2000) suggested that the conflict between students' alternative conceptions and targeted scientific concepts can be completely resolved under four conditions. This is based on Hashweh's (1986) suggestion that students should try to 
change or transform perceptions caused by discrepant events into their own alternative conceptions to confirm the existing conceptions. However, many studies report having tried to change the protective belt without changing the core of students' alternative conceptions.

Niaz (1998) stated that if students are given any opportunities to change conceptions, then they will try to change the soft core but will resist changes to the hard core by offering auxiliary hypotheses. In other words, it is a pretense disguising conceptual changes.

The two processes are represented in Figure 1.

This study addresses the promising Lakatosian "research program" theory and students' alternative concepts (rather than Kuhn's paradigm, which is not commensurable). When facing anomalous data, people make efforts to accommodate theories and materials (Kuhn, 1989). Consequently, our major objective was to adopt the Lakatosian methodology as a useful framework that students' concepts partly change.

Science educators could potentially use these frameworks to design conflict maps as a means of overcoming students' alternative conceptions and conducting science instruction. The conflict maps presented in Figure 2 show the components and suggested instructional sequence of such frameworks (Tsai, 2003).

Figure 2 shows the framework of a conflict map. A full description of the rationale behind using a conflict map was presented in Tsai (2000). The use of the conflict map is based on the research work of Tsai (2000), which extended the theoretical framework of Hashweh (1986). The use of conflict maps could help students seek a stable and desirable equilibrium between the conceptual schema they have already assembled and the perceptual information arising from the environ-

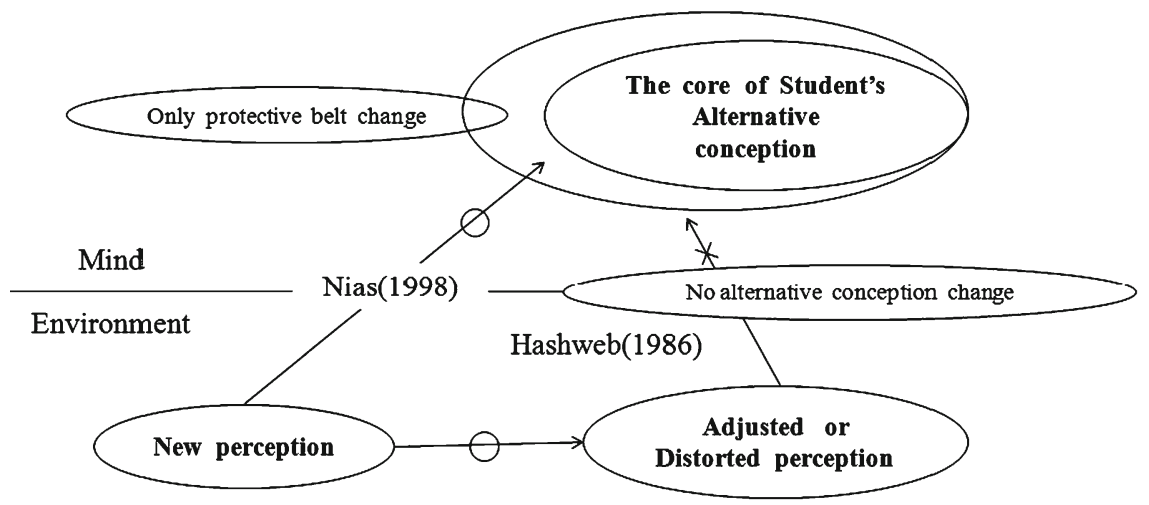

Figure 1. A student's typical responses to discrepant events 


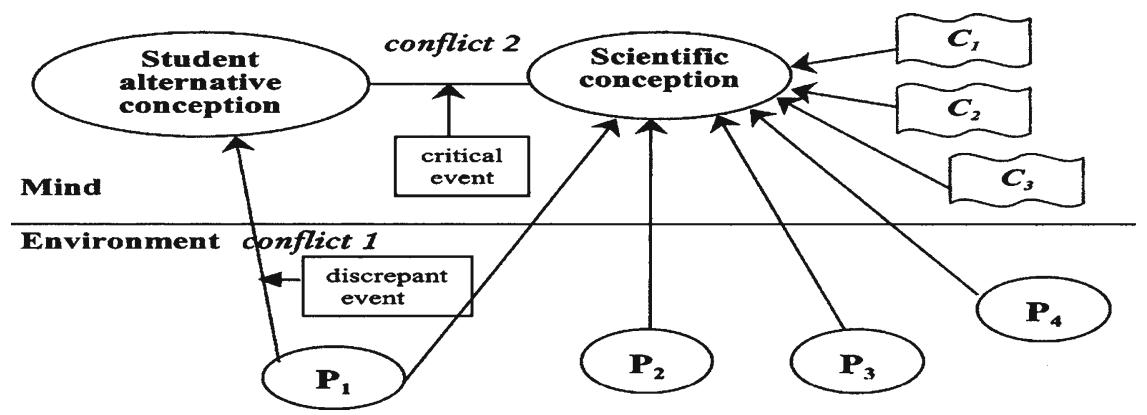

Note: $\mathrm{P} 1$ : the perception inducing a discrepant event

P2, P3, P4: other supporting perceptions

C1, C2, C3: relevant scientific conceptions

Figure 2. A typical conflict map (Tsai, 2003, p. 309)

ment. This study clarifies this use of conflict maps and explores and emphasizes the connections between alternative conceptions and scientific ideas. Educators often lament that science students tend to employ rote learning strategies for scientific knowledge and learn isolated bits of scientific facts. It is anticipated that the use of conflict maps may facilitate students' meaningful learning in science, as well as help students construct more integrated knowledge structures (Tsai, 2000). More specifically, the use of a conflict map asserts that students should resolve two conflicts during the process of conceptual change: between the new perception and students' alternative conceptions (conflict 1) and between students' alternative conceptions and scientific concepts (conflict 2; Hashweh, 1986). The resolution of conflict 1 does not necessarily resolve conflict 2 . Conflict 1 could be resolved through discrepant events and the resolution of conflict 2 could be achieved through using "critical events or explanations" and relevant perceptions $(\mathrm{P} 2, \mathrm{P} 3, \mathrm{P} 4 \ldots)$ and conceptions $(\mathrm{C} 1, \mathrm{C} 2, \mathrm{C} 3 \ldots)$ that explicate the scientific concept (Tsai, 2000, 2003).

The use of the conflict map not only presents the cognitive conflict or anomalous data but also assists students in exploring the connections between anomalous data, alternative conceptions, scientific conceptions, other knowledge, and related experiences, thus helping students engage in deep processing about the target scientific concepts. Because the use of the conflict map is developed on the basis of students' existing knowledge and related experiences, it is also consistent with the perspective proposed by Hewson \& Thorley (1989) that the conceptual change requirements of what is intelligible, plausible, and fruitful must be 
in the students' conceptions. However, instruction guided by the conflict map does not completely ignore the contextual/social aspects of conceptual change. For example, instruction guided by the conflict map highlights the importance of presenting anomalous data in the context of students' cultural experiences (e.g. the use of critical events). It also encourages students' participation in the social development of science knowledge, such as group discussion of discrepant and critical events. In this way, the contextual and social issues of conceptual change may be addressed (Tsai, 2005).

Although the use of conflict maps could potentially help students seek a stable and desirable equilibrium between the conceptual schema they have already assembled and the perceptual information arising from the environment, we consider prudent this conflict map based on Lakatosian methodology as follows as following items:

First, according to (Tsai, 2000), the frameworks of conflict maps may help students construct more integrated and scientifically sound knowledge structures about the target scientific concepts. However, it is necessary to emphasize that targeted scientific knowledge has a structure so that teachers would feel the need to use the framework educationally. For example, it is necessary to show that the scientific concept consists of the core concept and the protective belt supporting the concept because commensurability is low between the core concepts of the scientific concept and students' alternative conceptions.

Second, Tsai (2000) proposed that students could draw their own conflict maps as a metacognitive tool to review their ideas and monitor their processes of conceptual change. It is necessary to examine students' scientific concepts: to trace how their alternative conceptions change into scientific concepts, to understand the changes and their channels, and to make direct prescriptions. Therefore, the study traces the extent of core change of students' alternative concepts rather than the scientific percentage of correct answers. Furthermore, this study examines how helpful the suggested framework is for students by measuring the knowledge they attained.

Third, it is suggested that teachers should investigate whether students' alternative conceptions and scientific concepts are commensurable. Lakatosian methodology is open to commensurability. We believe that students' alternative conceptions have commensurability with scientific concepts, and we suggest that students' alternative concepts should be used as direct material. We believe that commensurability of students' alternative conceptions and scientific concepts exists in part. 


\section{How Should we Enhance Tsai's Conflict Map and Develop an Enhanced Conflict Map Based on Lakatosian Methodology?}

\section{Lakatosian Methodology}

The Lakatosian methodology of competing research programs provides a useful framework for the reconstruction of students' and teachers' understanding of science content. This methodology has previously been applied to interpret research in science education (Blanco \& Nias, 1997, 1998; Kelly, 1997; Chin \& Brewer, 1993; Girbert \& Swift, 1985; Linn \& Songer, 1991; Niaz, 1993, 1994, 1995).

According to Lakatos (1970), a research program consists of methodological rules: some tell us what paths of research to avoid (negative heuristic) and others tell us what paths to pursue (positive heuristic).

The negative heuristic of a research program isolates a "hard core" of propositions that are not exposed to falsification. The positive heuristic is a strategy for constructing a series of theories in such a manner that shortcomings at any particular stage can be overcome. As the dotted circle line indicates, a "protective belt" of auxiliary hypotheses is created around the hard core of non-falsifiable propositions (Losee, 2001, pp. $203-204)$.

\section{Theoretical Framework}

1. The history of science can be conceived as that of competing rival research programs (Lakatos, 1971, p. 103).

2. Scientists do not abandon a theory on the basis of contradictory evidence alone, and "there is no falsification before the emergence of a better theory" (Lakatos, 1970, p. 119).

3. The replacement of a degenerating program by a progressive one constitutes Lakatos's version of a scientific revolution (Chalmers, 1999, pp. 135 - 135).

4. Learning is an active process of knowledge construction (Tsai, 2000).

The Teaching Strategies of Enhanced Conflict Maps Based on Lakatosian Methodology

Understanding the student's alternative conceptions: negative and positive heuristic operation in existing research program 
Looking for the student's core belief (hard core) on a topic can be an appropriate starting point for teaching strategies.

Suggesting discrepant events: degenerative research program in an existing research program

Discrepant events engender cognitive conflict when coping with core beliefs' problem-solving strategies.

\section{Introducing the Scientific Concept: Refining Naïve Scientific Concept}

1. Students should have minimal understanding about the main core of the scientific concepts that will be studied in order to resolve conflict 1. Negative heuristic in a new research program.

2. The learning process should involve a critical event or explanation to address conflict 2 directly. Degenerative (old) and progressive (new) research programs.

3. Meaningful learning involves students constructing integrated knowledge structures which contain their prior knowledge and new (scientific) concepts. Positive heuristic forming minimal protective belt in a new research program via theoretical progressive problem shift.

4. Meaningful conceptual learning requires perceptual supports, examples, or phenomena derived from relevant theories. Positive heuristic refining protective belt in a new research program via empirical progressive problem shift.

\section{Reflecting the Results of Scientific Conceptual Change/Shift}

It is plausible to suggest that the results obtained in this study reflect a change/shift in the soft core of students' beliefs.

In Figure 3, the naïve scientific concept element indicates that in one research program, the core does not change; instead, auxiliary hypotheses verified through experiments are continuously added. Based on Lakatosian methodology, the structure of the enhanced conflict map (shown in Figure 3) and teaching sequences are as follows (Figure 4): Theories 1 and 2 describe rival hard cores, but theory 2 and theory 3 describe the same hard cores.

The Teaching Sequence of Enhanced Conflict Maps to Resolve Two Conflicts

The Condition of Resolving Two Conflicts. Hashweh (1986) suggested two types of cognitive conflicts: the conflict between students' precon- 


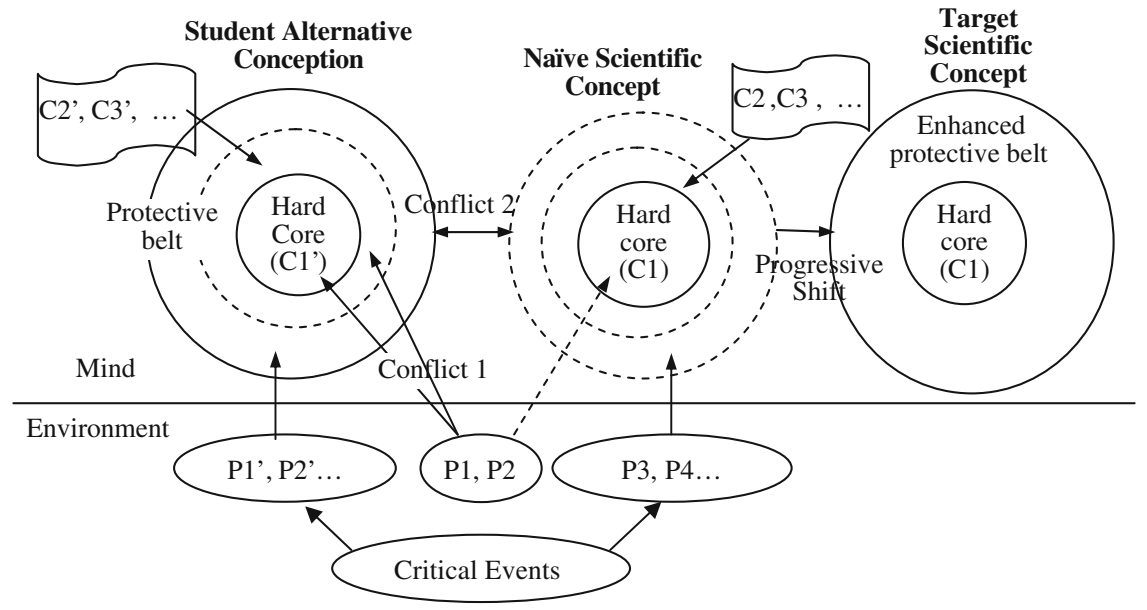

Note: P1', P2'.... : perceptions supporting Alternative conception

P1, P2 : perceptions including a discrepant event

P3, P4 , .. : other perceptions supporting Naïve scientific concept

C2', C3'... : relevant scientific concepts supporting Alternative conception C2,

C3, ... : relevant scientific concepts supporting Naïve scientific concept

Figure 3. Construction of an enhanced conflict map

ceptions and the present situation, and the conflict between preconceptions and scientific concepts.

The Condition of Resolving Conflict 1 (The Designed Discrepant Events). The structure of student alternative conceptions toward discrepant events should be explored, and students should have minimal understanding about the main core of the scientific concepts that will be studied to resolve suggested discrepant events.

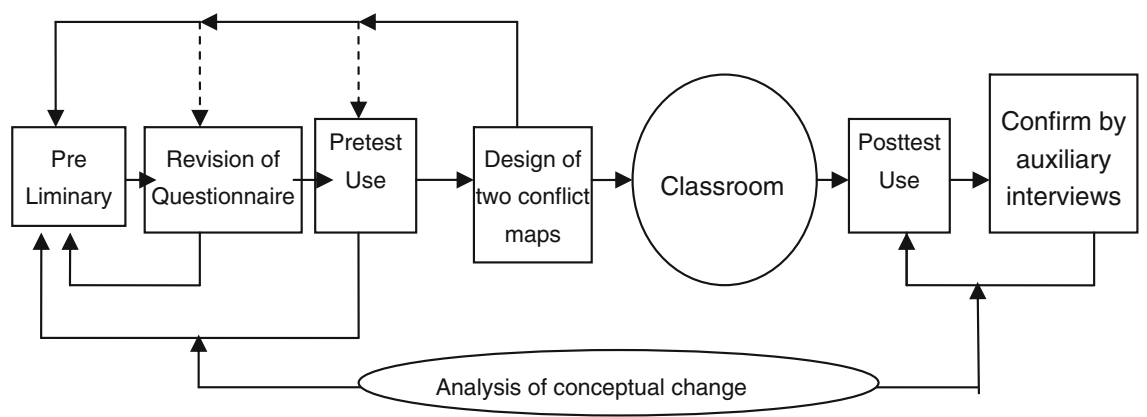

Figure 4. Research treatment 
The Conditions of Resolving Conflict 2 (Reinforced Naïve Scientific Concept). The learning process should involve a critical event or explanation to address conflict 2 directly. Then, other related scientific concepts will enhance the newly introduced scientific concept, and perceptual supports, examples, or phenomena derived from relevant concepts will refine the introduced scientific concepts.

\section{The Teaching Sequence of Enhanced Conflict Maps Based on Lakatosian Methodology}

The suggested teaching sequence is the discrepant event (or P1, P2) first, followed by the core of naïve scientific programs, the critical event, other scientific concepts $(\mathrm{C} 2, \mathrm{C} 3 \ldots)$, other supporting perceptions $(\mathrm{P} 3, \mathrm{P} 4 \ldots)$, and, finally $\mathrm{P} 1$ ' $\mathrm{P} 2$ '.... This information is presented in a flowchart, as follows:

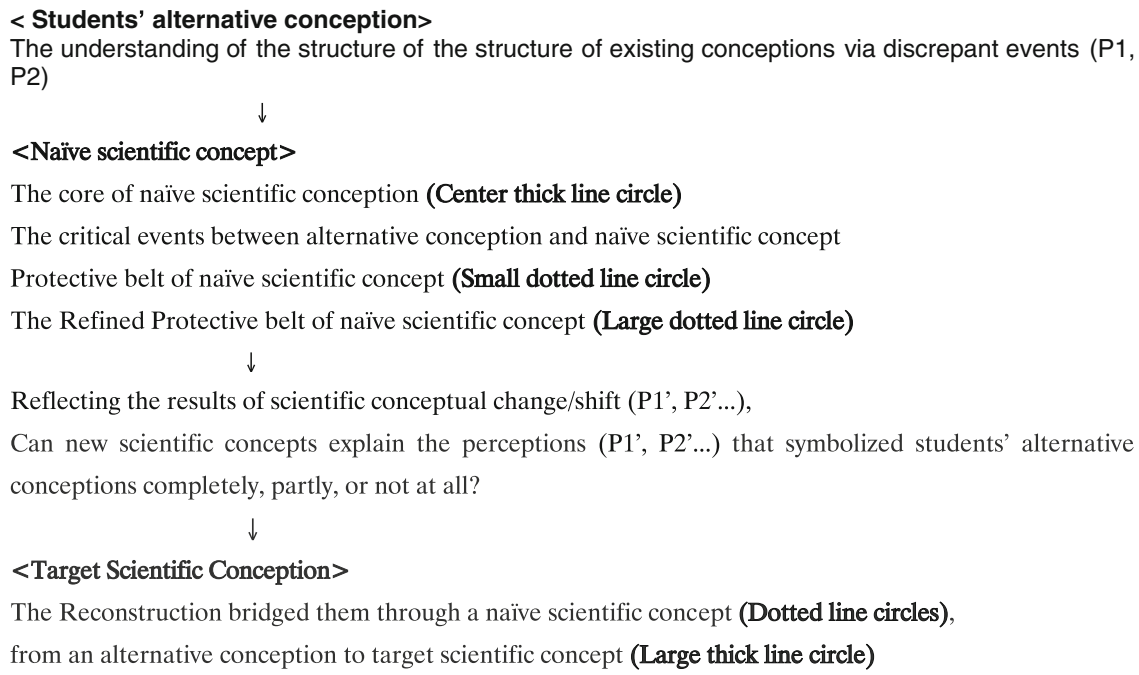

Methodology

The application of using enhanced conflict map to the photoelectric effect in the university classroom

Participants. For this study, freshmen taking the General Physics course during the spring semester of 2005 were selected as participants. Two classes $(n=49,49)$ were from the Department of Electronic Computer Engineering and one class of freshmen $(n=26)$ was from the Astronomy 
Course. All participants were students from C. National University, Korea.

They were divided into three groups according to teaching sequences:

1. The case emphasizing discrepant events only,

2. The case using the conflict maps (Tsai, 2000) after instruction,

3. The case using the enhanced conflict map before instruction and in turn arranging the conflict map of science history after instruction. Only students who described these exact statements about the conceptual change process and took part in all of the instruction processes were selected.

Research Treatment. Preliminary phase: The first phase consisted of developing questionnaires to investigate the structure of students' conceptions. The test included both open-type questions and selectivetype questions (shown in the Appendix). This preliminary test was given first, and then new questionnaires were developed according to the frequency of responses.

Revision of the questionnaire phase: In the second phase, new questionnaires that had been purely quantitative were taken for revision of questionnaires to frequency.

Design of the Data Collection Instruments. Study subjects were university freshmen. Therefore, the test adopted the questions used to determine learning ability for university entrance admission, called the preliminary examination for university entrance, after modifying answer examples to include both open-type questions and selectivetype questions. The testing method was as follows: the researcher selected physics questions from the questionnaire by Strike \& Posner (1992) and slightly modified them. The modified parts directed students to supplement selected answers or to state other reasons. If the stated reasons were unclear or differed from the selected answers, then they were excluded. On the basis of these responses, students' main viewpoints (Lakatos' 1970 hard core) were searched for by topic, and Niaz's (1998) criteria for examining core beliefs and alternative concepts were applied. Questions presenting discrepant events as determined by the preliminary test were used. A preliminary test was carried out in the fall semester of 2002. The preliminary test questions were open type. Using the answers, examples were made from the questions. 
The questions about alternative concepts focused on the photoelectric effect in the area of modern physics. Questions emphasized the core belief and one of the students' alternative concepts, showed the relationship with the soft core, and used graphs and questions to show discrepant events. The results were examined using the pretest paper without modification, and supplementary interviews were carried out.

The interviews were conducted as follows: two competitive theories were proposed and answers on the test's answer sheets were confirmed. The questions were then asked again to confirm the answers. If the answers on the questionnaires were not identical with the responses in the interviews, they were then excluded. The use of interviews was auxiliary; thus, the contents of the interviews are not presented in the analysis of results.

Pretest use stage: The revision pretest was administered on the first day of the semester for about $50 \mathrm{~min}$. Students' preconceptions were investigated.

Design of conflict maps stage: Tsai's conflict map emphasizes discrepant events and includes critical events or related concepts. Our enhanced conflict map emphasized the structure of students' alternative conceptions.

First map-classroom - final map stage: After the enhanced map was suggested and presented in advance, the students had classroom instruction to understand each situation shown in the suggested conflict map, for about $30 \mathrm{~min}$, it was arranged with the conflict map of science history.

Posttest use stage: Students' conceptual changes were measured. The first questionnaire was used without modification. Posttests were repeated after 1 week, and students were asked to state the reasoning behind their selections.

Analysis of conceptual change stage: The conflict map created by the researchers was provided before the classroom instruction. Oneweek after the learning process was completed according to the flow in our enhanced conflict maps, changes in students' alternative conceptions were investigated. Alternative conceptions refer to the ideas that students had before learning. The conceptions examined after 1 week were those that followed the discrepant events and critical events of the learning process. The answers were important in examining the structure of alternative conceptions. These questions partly represented discrepant events.

The pretest focused on finding out the structure of students' alternative conceptions according to the criteria for classification of students' responses as part of a Lakatosian core belief (Niaz, 1998). The test process was as follows: after students selected answers, the example selected the least often was chosen. Responses with a hard core were reported to have a relatively 
high rate of correct answers in the soft core. Of course, it was reported that students who chose correct answers showed a higher rate of correct answers than students who did not choose correct answers (Niaz, 1998). Niaz's study used question forms, but we used a questionnaire that allowed reasons to be given when selecting answers. Interviews with the students were carried out to supplement the test.

The pretest paper was used 1 week after students' active learning with the flow of our enhanced conflict maps. The focus of this test was not on the general rate of correct answers but on students' conceptual changes about the hard core. Figure 4 presents a flowchart that summarizes these research procedures.

The research subjects were university freshmen, so the test adopted questions from university entrance exams and modified answer examples. The test included both open-type questions and selective-type questions (shown in the Appendix). In the modified parts, the questions directed students to supplement selected answers or to state other reasons. If the stated reasons were unclear or different from the selected answers, then they were excluded. Questions presenting discrepant events identified by the preliminary test were used. The preliminary test was carried out in the fall semester of 2005 . The preliminary test questions were open type: questions that included many answers were being selected and used as examples.

The questions concerning alternative concepts focused on the photoelectric effect, a subject in modern physics. The questions emphasized the core belief and one of the students' alternative concepts, showed relations with the soft core, and used experimental graphs and questions that showed discrepant events. The results were examined with the pretest paper without modification, and interviews were carried out for supplementation.

The interview procedure was conducted as follows: two competitive theories were assumed and the answers on the answer sheets were confirmed. The students were then asked to check their answers again. If the answers on the answer sheets were not identical to the answers from the interviews, then they were excluded.

\section{Design of the Instructional Instruments. The enhanced conflict map} and conflict map for photoelectric effect: Based on Plank's work, Einstein proposed that light also delivers its energy in chunks so that light would then consist of little particles, or quanta, called photons. The energy of each photon has the energy of Plank's constant, times its frequency. The quantization concept applies to all regions of electro- 
magnetic radiation based on astrophysics and modern physics. Detailed investigation of this suggestion revealed some puzzling features that could not be understood on the basis of classical optics. We will discuss these using our enhanced conflict maps.

The conflict maps (shown in Figure 2) made by Tsai (2000) were expanded and enhanced by suggesting competing theories based on the framework of Lakatos' methodology. Our suggested "enhanced conflict map" is given in Figure 3. Progress was made according to our enhanced conflict map and Tsai's conflict maps. The enhanced conflict maps that included students' alternative concepts were suggested first, and the conflict map of science history (expressing scientists' concepts of the past) was suggested after the learning experience. The conflict maps suggested before learning suggest discrepant events and allow students to relinquish the core concepts, overcome cognitive conflicts with scientific concepts, and learn new concepts. Therefore, they were effective tools for learning new concepts.

Conflict maps about the photoelectric effect (shown in Figure 5) first show the structure of students' alternative concepts. The conflict map of science history about the photoelectric effect (shown in Figure 6) was suggested after learning to replace students' alternative conceptions in

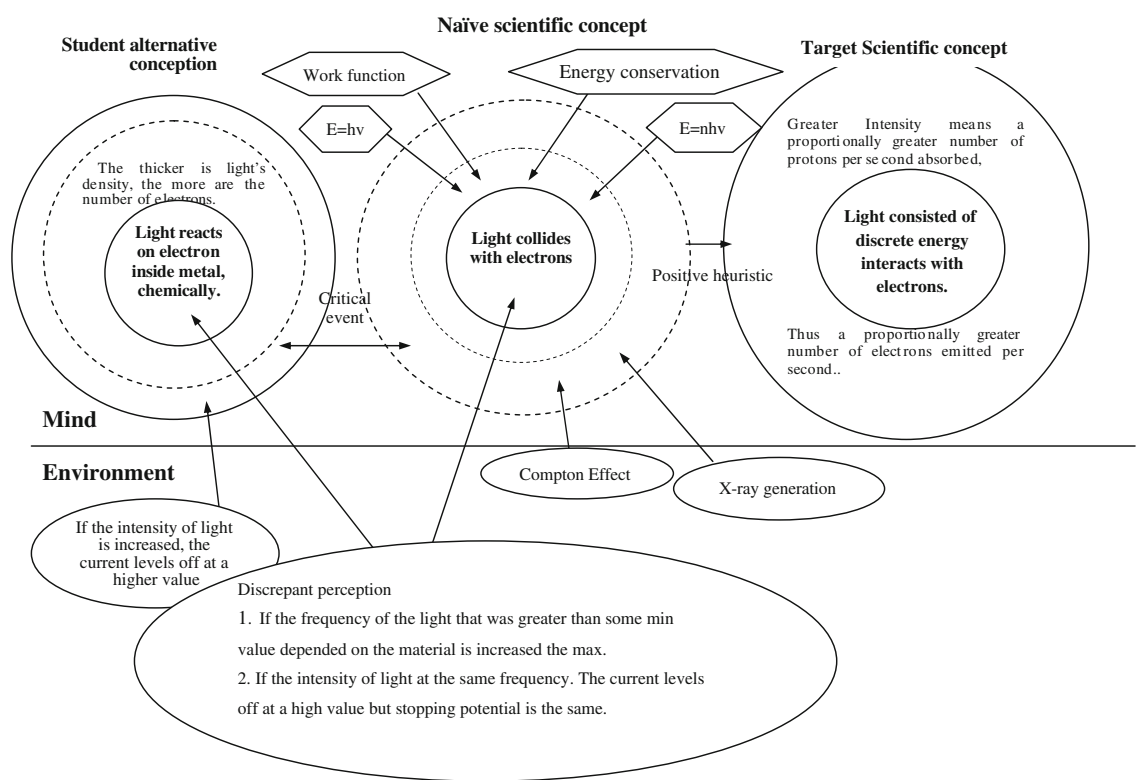

Figure 5. Our enhanced conflict maps based on Lakatosian methodology (the application of the photoelectric effect) 


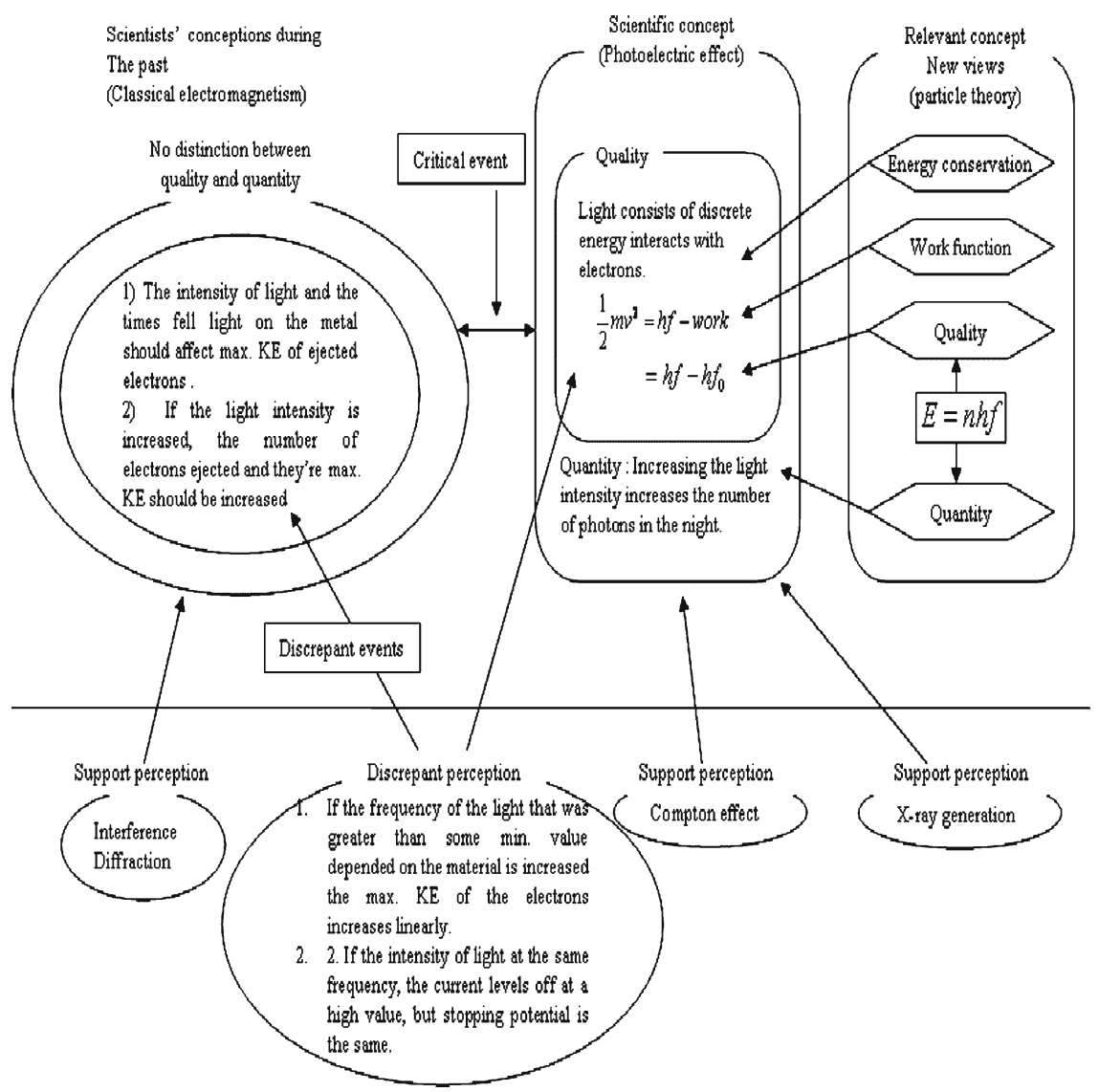

Figure 6. Conflict maps of science history (the application of the photoelectric effect)

favor of scientists' concepts from the past rather than showing the structure of alternative conceptions.

Critical events: The diameter of an atom is ten billionths of $1 \mathrm{~m}$, and an electron's diameter is even smaller. If light evenly spreads out from a radiant into space with an average frequency, then the energy colliding with such a small object will be reduced; consequently, it is impossible to pull electrons out of metal. When light collides with electrons, the photoelectric effect does not occur without the popping of electronic lumps. The case in which each $h f$ is large (quality) and the case in which small $h f$ is large (quantity) are discriminative. The classical theory of electronic magnetism does not distinguish energy from quantum, and it is explained with the quantum theory. In conclusion, when light collides with an object, it should be sharp like an awl point. Even if light shapes into particles, then those particles are not seen with the eyes; however, the photoelectric effect proves that the ray is a particle. 


\section{Analysis and Results}

\section{The Effects about using the Suggested Enhanced Conflict Map?}

We made up a questionnaire of open-type questions in advance, confirmed the most frequently selected examples, and developed a new answer sheet. According to the answers that the students selected, the examples were divided into two categories: scientific answers and incorrect answers. Next, students selected each reason and stated the reasons why they chose the examples. Tables 1 and 2 indicate these in the left column. The cases in which they did not state reasons or stated obscure reasons were excluded. If conceptual change results were confirmed after the learning process, then the questionnaire was used without modification.

This goal of the research was to change students' conceptions from alternative conceptions to scientific concepts using three cases: the first was a traditional case suggesting discrepant events only; the second was a

TABLE 1

Searching for the structure of alternative conceptions in question 1 (pretest)

\begin{tabular}{|c|c|c|c|c|c|}
\hline \multirow{2}{*}{\multicolumn{2}{|c|}{$\begin{array}{l}\text { Next, the reasons why they chose the } \\
\text { examples }\end{array}$}} & \multicolumn{3}{|c|}{ Number of responses \# (\%) } & \multirow{2}{*}{$\begin{array}{c}\text { The core concept of } \\
\text { alternative } \\
\text { conceptions that } \\
\text { students had } \\
\text { before instruction }\end{array}$} \\
\hline & & $\begin{array}{l}\text { Discrepant events } \\
\text { only: astronomy } \\
\qquad(n=31)\end{array}$ & $\begin{array}{l}\text { Our conflict } \\
\text { maps only } \\
(n=49)\end{array}$ & $\begin{array}{c}\text { Our conflict } \\
\text { maps and } \\
\text { conflict maps } \\
(n=49)\end{array}$ & \\
\hline \multirow{6}{*}{$\begin{array}{c}\text { First, } \\
\text { selection of } \\
\text { correct } \\
\text { answers }\end{array}$} & 1) & 0 & 0 & 0 & \\
\hline & 2) & 0 & 0 & 0 & \\
\hline & $\begin{array}{l}\text { 3) Over a certain } \\
\text { frequency, light } \\
\text { momentarily collides } \\
\text { with electrons; } \\
\text { consequently, ejected } \\
\text { electrons' maximum } \\
\text { energy is proportional to } \\
\text { rays' frequency. }\end{array}$ & $8(26)$ & 19(39) & 14(29) & \\
\hline & $4)$ & $5(16)$ & $1(2)$ & $1(2)$ & \\
\hline & 5)Others & & 0 & 0 & \\
\hline & Total correct answers & $13(42)$ & $20(41)$ & $15(31)$ & \\
\hline \multirow[t]{7}{*}{$\begin{array}{c}\text { First, } \\
\text { selection of } \\
\text { incorrect } \\
\text { answers }\end{array}$} & $\begin{array}{l}\text { 1) The longer the time of } \\
\text { taking in light, the bigger the } \\
\text { frequency, the more energy } \\
\text { stored in electrons inside } \\
\text { metal, the more active } \\
\text { chemical reaction, and the } \\
\text { bigger the maximum kinetic } \\
\text { energy of ejected electrons. }\end{array}$ & 14(45) & $26(53)$ & $25(51)$ & \\
\hline & $\begin{array}{l}2) \text {. } \\
\end{array}$ & $4(13)$ & $1(2)$ & $6(12)$ & ore \\
\hline & 3) & 0 & $1(2)$ & $1(2)$ & \\
\hline & 4) & 0 & 0 & $1(2)$ & \\
\hline & 5) Others & & $1(2)$ & $1(2)$ & \\
\hline & Total incorrect answers & $18(58)$ & $29(59)$ & $34(69)$ & \\
\hline & All students & $31(100)$ & $49(100)$ & $49(100)$ & \\
\hline
\end{tabular}


TABLE 2

Searching for the structure of alternative conceptions in question 2 (pretest)

\begin{tabular}{|c|c|c|c|c|c|}
\hline & & \multicolumn{3}{|c|}{ The number of correct answers \# (\%) } & The protective belt \\
\hline \multicolumn{2}{|c|}{$\begin{array}{l}\text { Next, the reasons why } \\
\text { students chose the examples }\end{array}$} & $\begin{array}{l}\text { Discrepant } \\
\text { perceptions } \\
\text { only: } \\
\text { Astronomy } \\
\quad(n=31)\end{array}$ & $\begin{array}{c}\text { Our conflict } \\
\text { map only: } \\
\text { physics }(n=49)\end{array}$ & $\begin{array}{l}\text { Two conflict maps: } \\
\text { physics } \\
(n=49)\end{array}$ & $\begin{array}{c}\text { of alternative } \\
\text { conceptions } \\
\text { students had } \\
\text { before class- } \\
\text { work }\end{array}$ \\
\hline \multirow{6}{*}{$\begin{array}{l}\text { First, } \\
\text { selection of } \\
\text { correct } \\
\text { responses }\end{array}$} & 1) & $12(39)$ & $11(23)$ & $6(12.5)$ & \\
\hline & $\begin{array}{l}\text { 2) The greater the } \\
\text { intensity of light, the } \\
\text { thicker its density, and } \\
\text { the larger the number } \\
\text { of electrons ejected in } \\
\text { reaction to the ray. As } \\
\text { a result, the metal foil } \\
\text { closes quickly. }\end{array}$ & $15(48)$ & $26(53)$ & $20(41)$ & $\begin{array}{l}\text { belt } \\
\text { Hard core }\end{array}$ \\
\hline & 3) & 0 & $3(6)$ & $10(20.5)$ & \\
\hline & 4) & 0 & $2(4.1)$ & 0 & \\
\hline & 5)Others & 0 & $2(4.1)$ & $2(4)$ & \\
\hline & Total correct answers & $27(87 \%)$ & $44(90 \%)$ & $38(78 \%)$ & \\
\hline \multirow{7}{*}{$\begin{array}{l}\text { First, } \\
\text { selection } \\
\text { of incorrect } \\
\text { response }\end{array}$} & 1) & & 0 & 0 & \\
\hline & 2) & & 0 & 0 & \\
\hline & $3)$ & $1(3)$ & 0 & $1(2)$ & \\
\hline & $\begin{array}{l}\text { 4) When exposed to } \\
\text { ultraviolet rays, } \\
\text { electrons are ejected. } \\
\text { They are reflected } \\
\text { after colliding against } \\
\text { the zinc plate, but } \\
\text { electrons are not } \\
\text { generated from the } \\
\text { zinc plate. }\end{array}$ & $3(10)$ & $2(4)$ & $3(6)$ & \\
\hline & 5) Others & 0 & $3(6)$ & $7(14)$ & \\
\hline & $\begin{array}{c}\text { Total incorrect } \\
\text { answers }\end{array}$ & $4(13)$ & $5(10)$ & $11(22)$ & \\
\hline & All students & $31(100 \%)$ & $49(100 \%)$ & $49(100 \%)$ & \\
\hline
\end{tabular}

case that used our enhanced conflict map only; and the third was a case that used two conflict maps. The focus of this study was to observe the significant effects from case to case.

Searching for the Structure of Students' Alternative Conceptions. Learners' preliminary knowledge is a requisite condition for constructing meaning (Pines \& West, 1986). It is very proper that the interaction between new knowledge and existing knowledge is the most important factor in the process of Lakatosian conceptual change strategies because it considers students' beliefs and scientific theories to be competitive research programs.

This study primarily investigates the structure of students' alternative conceptions. The secondary focus of this study is the effects of students' alternative conceptual change after actively using conflict maps that conflict with the core alternative conceptions. Thus, we applied and used Niaz's criterion as follows to investigate the structure of students' alternative (rather than scientific) concepts. 
Niaz (1998) suggested the following as criteria for confirming the structure of students' alternative conceptions; they are the main part of Lakatos' core belief. We applied the suggested criteria.

Criterion 1: Deletion criterion. Faced with a similar problem in Piagetian theory, Beilin (1985) proposed a "deletion criterion": "If a construct in the theory can be deleted without apparent damage to the identification of the theory such as Piaget's, then it is not part of the hard core. If, on the other hand, deletion detracts materially from the theory or alters it in irreparable ways, then it is part of the hard core" (pp. $109-110$ ).

Criterion 2: Hard core and protective belt propositions. According to Chinn \& Brewer (1993), Lakatos (1970) distinguished between two types of propositions within a theory: hard core propositions and protective belt propositions. Hard core propositions cannot be altered without scrapping the entire theory, but protective belt propositions can be altered while preserving the key, central hypotheses.

Criterion 3: Auxiliary hypotheses. Given the opportunity for conceptual change, students invariably tend to accept changes in their frameworks (soft core) but resist changes to the hard core by offering "auxiliary hypotheses."

\section{Conceptual Analysis on Pretest Questions (The Structure of Alternative} Conceptions). Hard core propositions (shown in Table 1) in students' alternative conceptions: "The light used in the photoelectric effect and the electrons inside the metal store energy, go through a chemical reaction with light, and then are ejected." This explanation is definitely discrepant from the present modern theory. Nevertheless, the response ratios of example (1) were $45 \%, 53 \%$, and $51 \%$, respectively, among the first incorrect answers in question $1(58 \%, 59 \%$, and $69 \%$, respectively). Thus, we consider this explanation as being hard core for obstinate conceptual change to target modern science because Niaz (1998) considered responses that were the most obstinate of incorrect answers as a hard core about chemical equilibrium.

Protective belt propositions (soft core, shown in Table 2) in students' alternative conceptions: Their selection ratios of example (2) were $87 \%, 90 \%$, and $74 \%$, respectively, the correct answer ratio in question 2 (87\%, 90\%, 74\%, respectively).

As suggested previously, Q1 can be considered a "core belief" of students' understanding, whereas Q2 represents the dispensable part (soft 
core/positive heuristic). Results from this study show that students consider Q1 to be the most difficult.

Scientific response rates of students who definitely know the particle theory of light in question 1 (that the maximum kinetic energy of ejected electrons is not related but is proportional to the light frequency in cases over a certain frequency) for correct answers were $42 \% 41 \%$, and $31 \%$, respectively. The exact scientific response rates (example 3) were $26 \%$, $39 \%$, and $27 \%$, respectively. They were $75 \%(n=8-6), 68 \%$ $(n=19-11)$, and $79 \%(n=14-11)$, respectively, in question 2 .

Thus, we consider this explanation as a oft core for less obstinate conceptual change to target modern science because Niaz (1998) considered a response that was the relative less obstinate of correct answers as a soft core about chemical equilibrium

Students who responded correctly to Q1 performed extremely well on Q2. It is plausible that students' misconception of (Q1) represents the hard core (negative heuristic) of their framework in the Lakatosian sense (Lakatos, 1970; Niaz, 1998). According to the Lakatosian framework, student understanding of Q2 would represent the soft core (positive heuristic) of their framework, which offers relatively less resistance to conceptual change.

In conclusion, students had a core frame (Q1) that means that light and electrons inside the metal cause a chemical reaction and the electrons are ejected using an assistant hypothesis that the stronger the light, the denser it is and the more collisions of light and electrons occur (Q2). Taking their cue from Lakatos, Chin \& Brewer (1993) emphasized that students resist changes in their major theoretical frameworks (e.g. Q1) by accepting the "auxiliary hypotheses" (Q2).

A scientific understanding of Q1, namely that "the maximum kinetic energy of ejected electrons from the colliding of light and metal's electrons is proportional to the light frequency," brings about the following conceptualization:

In Q2, the concept that "light gets stronger" means that the number of collisions between light and metal increases; the number of ejected electrons increases as the number of light collisions increase and the metal foil of the electroscope charged with the negative electrode closes quickly.

This shows quite clearly how Q1 affects the understanding of Q2. However, deletion of Q1 may lead to a "scrapping" of the entire framework of students' understanding. Deletion would amount to solving this problem without the understanding provided by Q1.

Summarizing, an application of Beilin's "deletion" criterion (criterion 1) shows that deletion of student understanding of Q1 (core belief) would lead to a "scrapping" of the entire framework of student understanding 
(criterion 2), and hence, they use Q2 (auxiliary hypotheses) precisely to protect their core belief (criterion 3).

Effects of conceptual change after instruction: To determine the results of conceptual change, 1 week after construction, the questionnaire in the pretest was used without modification, and supplemental interviews were performed.

The purpose of these tests and interviews was to determine the core of alternative concepts and to show the protective belt's role in influencing students' concept changes. The aim was not to determine the correct answer ratio but to understand students' conceptual change (change of the core).

The following instruction methods were used: instruction with discrepant perceptions only; instruction with our enhanced conflict maps, including students' alternative concepts; and instruction with our conflict maps comparing the arrangement of conceptions from Tsai's conflict maps with the past scientists' concepts. To compare conceptual change rates between the instruction strategies, the responses indicating that the core of students' alternative conceptions changed into the core of target scientific concepts (the final goal of this study) were examined.

On the whole, the correct answer rate showed good results. The change ratio of the protective belt $(89 \%, 60 \%$, and $89 \%$, respectively) was higher than changes of the core (shown in Table 3). However, the main goal of our study was to investigate how the core of students' alternative concepts changes into the core of scientific concepts. In other words, in the case of suggesting discrepant events only, $50.0 \%$ of students achieved our goal, whereas in the case of suggesting the conflict map, only $58 \%$ of students achieved our goal. Furthermore, when we suggested two conflict maps, $64 \%$ of students achieved our goal (shown in Table 3).

In conclusion, students' core beliefs were resistant to change, but the protective belt was easily changed. Also, the affirmative effects were shown when two conflict maps were introduced in turn.

The limitation of using the enhanced conflict maps: Our study aimed to change students' conceptions into scientific concepts. Interviews were performed to supplement the questionnaire survey. However, conceptual change processes were not continually followed up individually or in small groups. For example, the factors that make students retain alternative concepts reflect the endurance of students' beliefs, motivation, etc. As in typical college lectures, the instructions were given by asking questions and giving explanations. The instructions focused not 
USING AN ENHANCED CONFLICT MAP BASED ON LAKATOSIAN METHOLOGY 1155

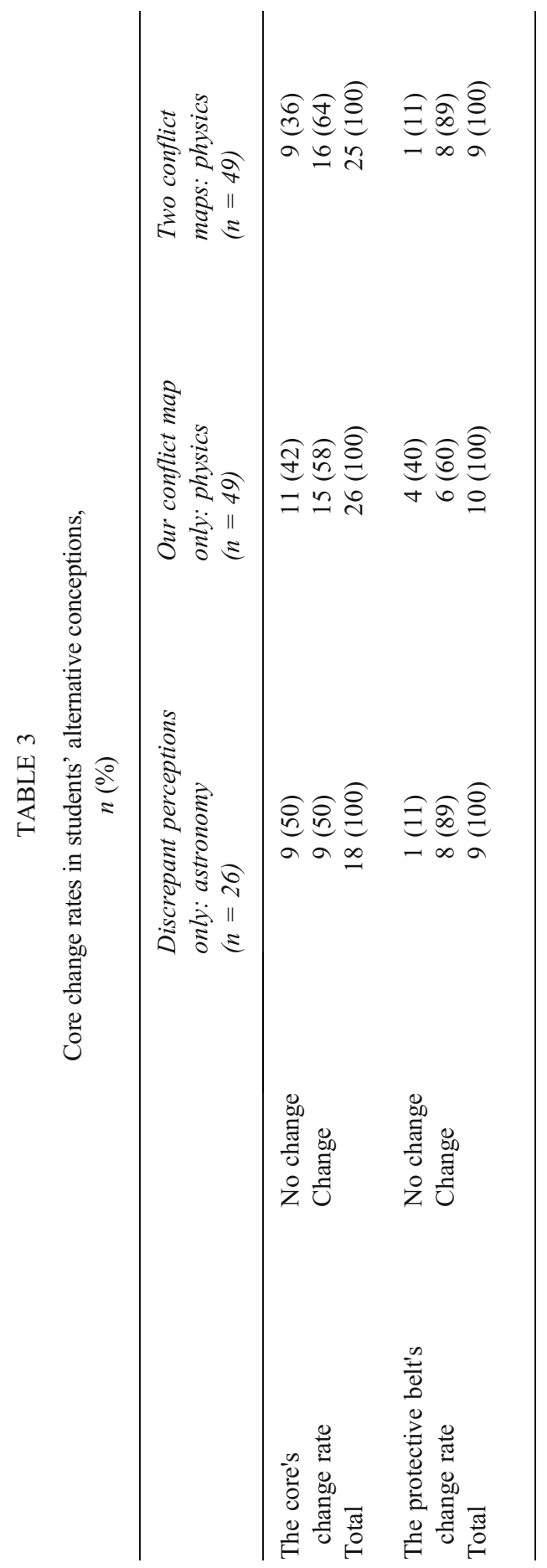


on student individuals' conceptual changes themselves but on the overall conceptual changes. Knowledge of subjects like modern physics and classical physics are not obtained through everyday life experience but through scientific learning. However, the suggested use of these methods can be applied to individual conceptual changes. Finally, in order to change students' alternative conceptions into scientific concepts, discrepant events should be suggested and various types of learning should be researched as our suggestions are not absolute. Responses to discrepant events become critical clues that enable us to approach scientific concepts. Therefore, the questionnaire survey and interviews should be further refined.

Finally, a limitation of this study is that the Lakatosian framework that we used is not applicable to all areas of science.

\section{Discussion AND Conclusions}

\section{A Lakatosian Conflict Map involving teaching strategies}

Niaz (1998) said that if students are given any opportunities to change their conceptions, then they will try to change their soft core but will resist changes to the hard core by offering auxiliary hypotheses. In other words, it is a pretense disguising conceptual changes. The Lakatosian methodology of competing research programs provides a useful framework for the reconstruction of students' and teachers' understanding of science content.

The conflict map is mainly based on the use of cognitive conflict. The conflict map in this study and those in other related studies (Tsai, 2000, 2001, 2003, 2005) adequately integrate students' existing experiences or knowledge, new theories, anomalous data, and other conceptual as well as perceptual supports to facilitate the development of scientific conceptions. Tsai (2003) reported that instruction guided by the frameworks of the conflict map is effective in helping students develop richer and more integrated cognitive structures with regard to simple series electric circuits. Tsai (2005) also applied the conflict map to conceptual learning about the causes of the seasons.

The use of conflict maps may help students seek a stable and desirable equilibrium between the conceptual schema they have already assembled and the perceptual information arising from the environment. We carefully considered this conflict map based on Lakatosian methodology as follows:

First, it is necessary to emphasize that targeted scientific knowledge has a structure so that teachers would need to use the framework educationally. For example, it is necessary to show that the scientific 
concept consists of the core concept and the protective belt supporting the concept. This is because commensurability is low between the core concepts of the scientific concept and students' alternative conceptions.

Second, the study traced the extent of the core change of students' alternative concepts rather than the scientific percentage of correct answers. Furthermore, the study examined how helpful the suggested framework is for students by measuring how much knowledge they attained.

Third, teachers should investigate whether students' alternative conceptions and scientific concepts are commensurable. The Lakatosian methodology is open to commensurability, so we believe that students' alternative conceptions have commensurability with scientific concepts. We suggest that students' alternative concepts should be used as direct materials. We believe that commensurability of students' alternative conceptions and scientific concepts coexists in part.

How Should We Enhance Tsai's Conflict Map and Develop a New Enhanced Conflict Map Based on Lakatosian Methodology?

Our enhanced conflict map of naïve scientific concepts shows that in one research program, the core does not change: instead, auxiliary hypotheses, verified through experiments, are added continuously. Based on Lakatosian methodology, the structure of the enhanced conflict map (shown in Figure 3) and teaching sequences are as follows (Figure 4): Theory 1 and theory 2 describe rival hard cores, but theory 2 and theory 3 describe the same hard cores. However, Tsai's conflict map was not divided by the structure of students' alternative conceptions.

\section{Application of Enhanced Conflict Map to the Photoelectric Effect in the University Classroom and Analysis the Application Effects of the Enhanced Conflict Map Suggested by This Research}

In our study, the critical clue to understanding the conceptual change process is how students respond when they face discrepant perceptions. Our study consisted of two areas: the core belief that would resist opposition in students' alternative concepts and the protective belt that would change easily and is partly commensurable with scientific concepts. The framework of our study was the competitive theories that are commensurable; they align with the Lakatosian methodology that reconstructs the history of science. Under these hypotheses, we 
tried to understand the structure of students' alternative conceptions by selecting the photoelectric effect, a concept found in modern physics and astrophysics. Our study emerged from the hypothesis that the core of students' alternative conceptions originated in classical physics, which is not consistent with modern physics.

According to this research, one of the most significant alternative conceptions (misconceptions) that students hold is that "The longer the time of taking in light, the bigger the frequency, the more energy stored in electrons inside metal, the more active chemical reaction, and the bigger the maximum kinetic energy of ejected electrons." In our study, it was found that in spite of misconceptions, students who understood the most significant misconception subsequently performed relatively well on other related aspects of the statement (The greater the intensity of light, the thicker its density, the larger the number of electrons ejected in reaction to the ray. As a result, the metal foil closes quickly). These results indicate that student conceptualization of the misconception is more resistant to instruction in the traditional classroom and thus can be considered a major theoretical framework (core belief) of student misconceptions.

On the other hand, students who responded correctly to Q1 performed extremely well on Q2. It is plausible that student misconception of (Q1) represents the hard core (negative heuristic) of their framework in the Lakatosian (Lakatos, 1970) sense.

Again, according to the Lakatosian framework, student understanding of Q2 would represent the soft core (positive heuristic) of their framework, which offers relatively less resistance to conceptual change.

We carried out a preliminary test and then carried out an interview to determine the core of students' alternative concepts and the protective belt. Next, we examined how concepts changed after instruction. Furthermore, we investigated how the core of students' alternative conceptions changed using our enhanced conflict maps (Lakatosian methodology) and conflict maps (science history). Research results were as follows.

First, when facing discrepant events opposing alternative conceptions, students believed that changes of the protective belt were real, although these did not include real changes of the core. Therefore, it was difficult for the core belief of students' alternative conceptions to change.

Second, in order to see the core change effects of students' alternative concepts, we found that using our enhanced conflict maps (including students' alternative conceptions and Tsai's conflict maps with past 
USING AN ENHANCED CONFLICT MAP BASED ON LAKATOSIAN METHOLOGY 1159

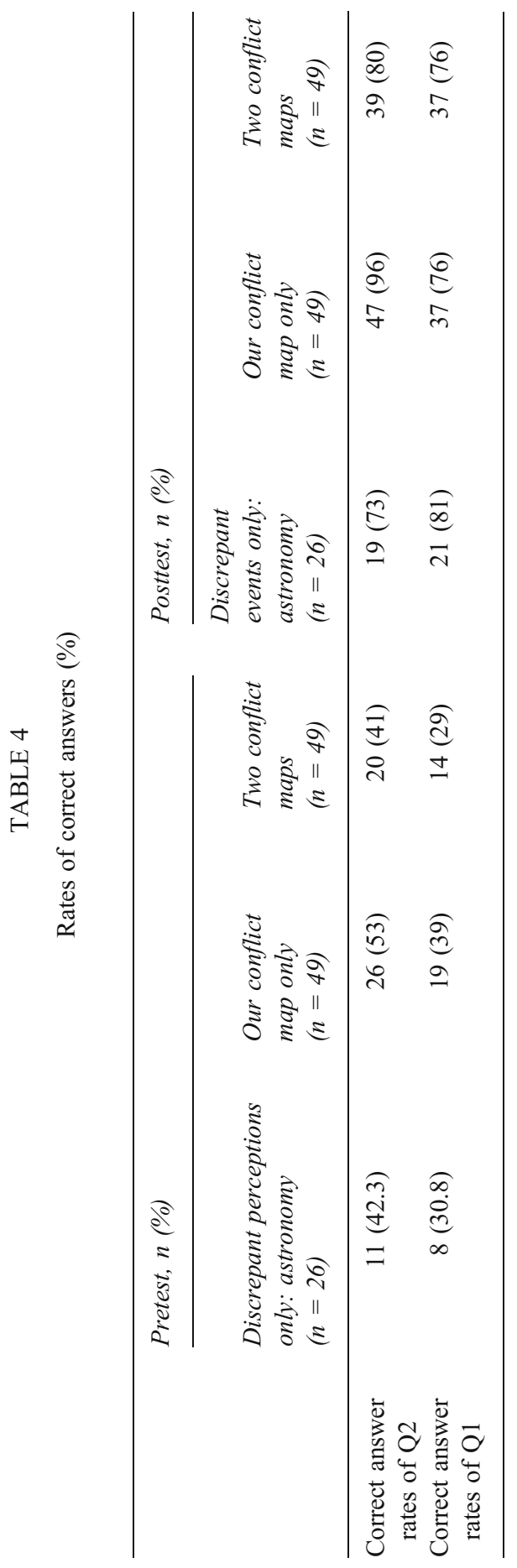


scientists' concepts) is more effective than using our conflict map only. If we neglected the instruction processes and suggested discrepant events only, then real conceptual changes did not occur.

Third, the results of this study suggested as a strategic starting point that students' alternative conceptions are changed into scientific concepts. Also, this study asserted that the core of alternative concepts and the protective belt should be identified so that they can be changed into scientific ones. This study showed that an area of modern physics (the photoelectric effect) tried to change the protective belt instead of changing the core of students' alternative conceptions, a different attitude from that of classical physics.

Fourth, the evaluation scale of science teachers/students should encompass the change in students' concepts or preconceptions. If we see students' conceptual change as learning, then the extent of those changes must be represented on the evaluation scale. A simple statement of correct answer percentages (Table 4) is not a correct evaluation. In other words, it is necessary to confirm the extent of change of students' core beliefs, which shows the real extent of change.

\section{Discussion of the Implications for Science Education}

The acquisition of better understanding may not correspond with having the "right answer." The philosophy and history of science (our enhanced conflict map), along with the attitude of the teacher and the nature of instruction, may be helpful here. Students' responses toward discrepant events based on their alternative conceptions are not wrong, but they reflect the ideas of earlier scientists. Therefore, this study asserted that students would have a basic framework that conflicts with modern scientific concepts. Scientists' concepts from the past are not identical with the students' alternative conceptions in the present, but they partly agree with each other.

\section{ACKNOWLEDGement}

I would sincerely like to thank Professor Jinwoo Jeong, President of Korea Association for Science Education, and Professor Chun-Hwey Kim of Chungbuk National University for encouraging me to put my work on paper. I would also like to thank, Professor Dong-Hyun Chae of Jeonju National University of Education, and Professor Jongwon Park of Chonnam National University for their efforts in making the manuscript much more readable. 
Open Access This article is distributed under the terms of the Creative Commons Attribution Noncommercial License which permits any noncommercial use, distribution, and reproduction in any medium, provided the original author(s) and source are credited.

APPENDIX

The questions of the test (the photoelectric effect) for examining the structures of students' alternative concepts and scientific conceptual change

Question 1. Changing rays' frequency with the lapse of time, by using a phototube, as the graph figure shows, and measuring maximum kinetic energy of ejected electron shown in the zinc metal plate
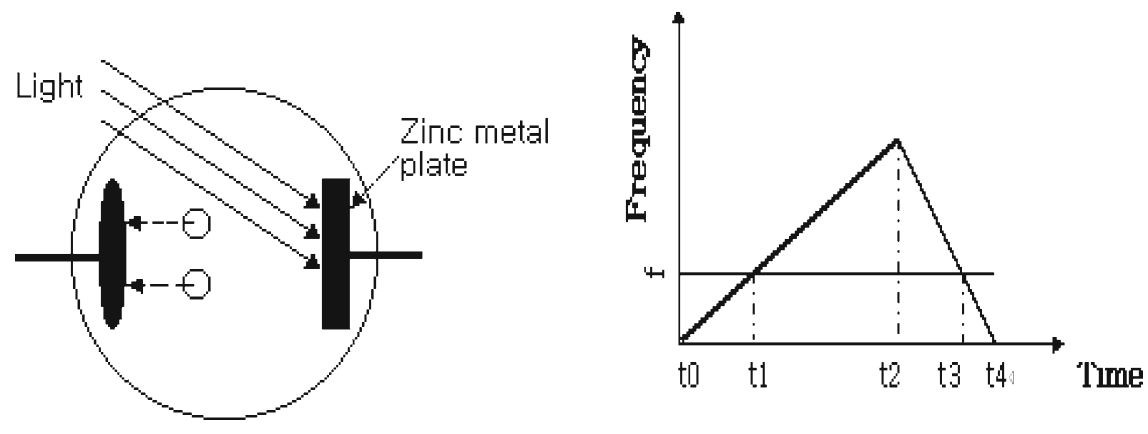

A. Which graph correctly shows changes to the maximum kinetic energy of the ejected electron according to time? (This refers to "threshold frequency value for a zinc surface" in the above graph. Select one answer only.)

1)

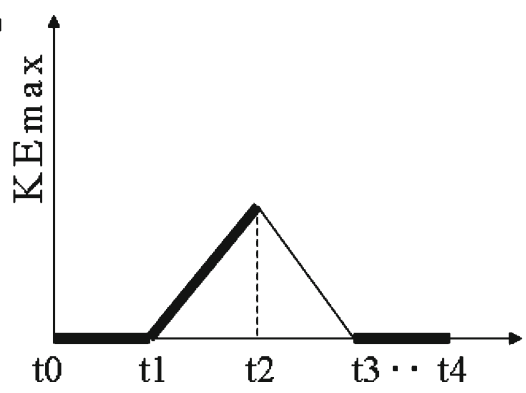

2)

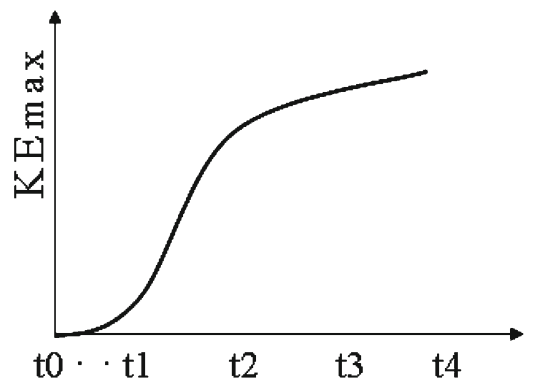


B. Which example correctly explains the reason for your answer in the above question?

(1) The longer the ray exposure, the bigger the frequency of light, the more active the chemical reaction of the light and the metal's electron, and the larger the maximum kinetic energy of the ejected electron.

(2) As the light's frequency increases, the strength of light increases on the electron inside the metal.

(3) Over a certain frequency, light collides against the electron in a moment. As a result, the maximum kinetic energy of the ejected electron becomes proportional to frequency regardless of time.

(4) Even in the case of a small frequency, momentary collision occurs so that kinetic energy is proportional to frequency regardless of time.

(5) Others. (After you choose one answer out of the above examples, add more explanation, and if you have different reasons, state them.)

Question 2. In the experiment, the zinc plate generates electrons because of the ray.

(Method of experiment)

After charging the electroscope to negative (-), it emit rays, such as disinfectant ultraviolet rays, on the zinc plate.

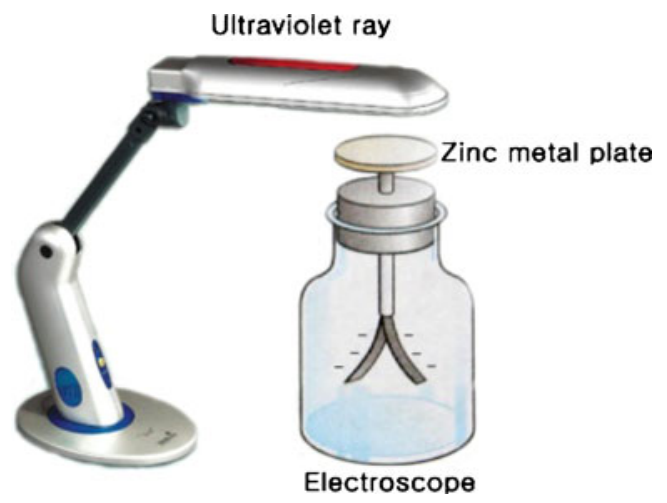


(Results of experiment)

The greater the intensity of the ultraviolet ray, the more quickly the electroscope's metal foil closes.

A. Is this correct after the experiment? (Choose one answer only.)

(1) Correct (2) Incorrect

B. What is the reason for choosing your answer above?

(1) The greater the intensity of light, the more energy is stored, the more active the energy movement becomes, and the more quickly the electron inside the metal is ejected. As a result, the metal foil closes quickly.

(2) The greater the intensity of light, the thicker its density is, and the more electrons are ejected in reaction to the ray. As a result, the metal foil closes quickly.

(3) The greater the intensity of light, the bigger the quantity of energy stored by electrons, the more active the energy movement of electrons consisting metal becomes, the bigger the number of electrons ejected from the atom is. As a result, the metal foil opens quickly.

(4) The greater the intensity of light, the bigger the number of electrons ejected from the mercury lamp is. As a result, they collide with electrons on the zinc plate, and then collided electrons are ejected.

(5) Other. (After you choose one answer out of the above examples, add more explanation, and if you have different reasons, state them).

Main interview: This interview will examine students' conceptual changes and confirm a clear structure of students' alternative concepts after finding out the core and the protective belt of students' alternative concepts using the questionnaire survey. Main questions were made for students who do not have scientific concepts but alternative concepts on the basis of the questionnaire paper.

Showing question 1 to the interviewee:

Q1: The longer the time giving out light, the bigger is the frequency of the ray and the more the energy is stored inside metal's electrons. As a result, do you think that the rate of the maximum kinetic energy of 
the ejected electron becomes bigger? Or, do you think that over a certain frequency, light collides against the electron in a moment regardless of time, and as a result, maximum kinetic energy of the ejected electron becomes proportional to frequency?

A1;

Showing question 2 (in case the experimental result is correct.).

Q2: The greater the intensity of sterilization, the greater becomes the electrons' movement by heat, as a result. Do you think that the metal foil closes quickly? Or, is it correct that the greater the strength of sterilization, the greater gets the density of light, the bigger gets the collision frequency, the bigger the number of ejected electrons, so as a result, the metal foil closes quickly?

A2:

\section{REFERENCES}

Beilin, H. (1985). Dispensable elements in Piaget's theory: One the core of Piaget's research program. In T. S. Evans (Ed.), Genetic epistemology: Yesterday and today (pp. 107-125). New York: City University of New York.

Blanco, R. \& Nias, M. (1997). Epistemological beliefs of students and teachers about the nature of science from "Baconian inductive ascent" to the "irrelevance" of scientific laws. Instructional Science, 25(3), 203-231.

Blanco, R. \& Nias, M. (1998). Baroque tower on a gothic base: A Lakatosian reconstruction of students' and teachers' understanding of structure of the atom. Science \& Education, 7(4), 327-360.

Brewer, W. F. \& Chinn, C. A. (1991). Entrenched beliefs, inconsistent information, and knowledge change. In L. Birnbaum (Ed.), The International Conference of the Learning Science: Proceedings of the 1991 Conference (pp. 67-73). Charlottesville: Association for the Advancement of Computing in Education.

Chalmers, A. F. (1982). What is this thing called science? (2nd ed.). Miton Keynes: Open University Press.

Chalmers, A. F. (1999). What is this thing called science? (3rd ed.). Cambridge: Hackett.

Chin, C. A. \& Brewer, W. F. (1993). The role of anomalous data in knowledge acquisition: A theoretical framework and implications for science instruction. Review of Educational Research, 63(1), 1-49.

Chinn, C. A. \& Brewer, W. F. (1998). An empirical test of an taxonomy of responses to anomalous data in science. Journal of Research in Science Teaching, 35(6), 623-654.

Clement, J. (1982). Students' preconceptions in introductory mechanics. American Journal of Physics, 50(1), 66-71.

Driver, R., Guesne, E. \& Tiberghien, A. (1985). Children' ideas in science. Milton Keynes: Open University Press. 
Dunbar, K. (1989). Scientific reasoning strategies in a simulated molecular genetics environment. Proceedings of the Eleventh Annual Conference of the Cognitive Science Society (pp. 426-433). Hillsdale: Erlbaum.

Duschl, R. A. \& Gitomer, D. H. (1991). 'Epistemological perspectives on conceptual change; Implications for educational practice', Journal of research in science Teaching, $28,839-858$.

Girbert, J. K. \& Swift, D. J. (1985). Towards a Lakatosian analysis of the Piagetian and alternative conceptions research programs. Science \& Education, 69, 681-696.

Hashweh, M. Z. (1986). Toward an explanation of conceptual change. European Journal of Science Education, 8(3), 229-249.

Heller, P. M. \& Finely, F. N. (1992). Variable uses of alternative conceptions: A case study in current electricity. Journal of Research in Science Teaching, 29, 259-275.

Hewson, P. W. \& Thorley, R. T. (1989). The conditions of conceptual change in the classroom. International Journal of Science Education, 11, 541-553.

Kelly, G. J. (1997). Research traditions in comparative context: A philosophical challenge to radical constructivism. Science \& Education, 81(3), 355-375.

Kitchener, R. F. (1987). Genetic epistemology, equilibration and the rationality of scientific change. Studies in History and Philosophy of Science, 18(3), 339-366.

Kuhn, T. S. (1970). The structure of scientific revolutions. Chicago: University of Chicago Press.

Kuhn, D. (1989). Children and adults as intuitive scientists. Psychological Review, 96, 674-689.

Lakatos, I. (1970). Falsification and the methodology of scientific research programmes. In I. Lakatos \& A. Musgrave (Eds.), Criticism and the growth of knowledge. Cambridge: Cambridge University Press.

Lakatos, I. (1971). History of science and its rational reconstructions. In R. C. Buck \& R. S. Cohen (Eds.), Boston studies in the philosophy of science, vol. VII. Dordrecht: Reidel.

Lakatos, I. (1981). History of science and its rational reconstruction. In I. Hacking (Ed.), Scientific revolutions. Oxford: Oxford University Press.

Linn, M. (1986). Learning more with computers as lab partners. Berkeley: University of California.

Linn, M. C. \& Songer, N. B. (1991). Teaching thermodynamics to middle school students: What are appropriate cognitive demands? Journal of Research in Science Teaching, 28, 885-918.

Losee, J. (2001). A historical introduction to the philosophy of science (4th ed., pp. 203204). New York: Oxford University Press.

Niaz, M. (1993). Progressive problem shifts between different research programs in science education: A Lakatosian perspective. Journal of Research in Science Teaching, 30(7), 757-765.

Niaz, M. (1994). Enhancing thinking skills: Domain specific/domain general strategiesA dilemma for science education. Instructional Science, 22(6), 413-422.

Niaz, M. (1995). Progressive transitions from algorithmic to conceptual understanding in student ability to solve chemistry problems: A Lakatosian interpretation. Science \& Education, 79(1), 19-36.

Niaz, M. (1998). A Lakatosian conceptual change teaching strategy based on student ability to build models with varying degrees of conceptual understanding of chemical equilibrium. Science \& Education, 7(2), 107-127. 
Park, J. \& Kim, I. (1998). Analysis of students' responses to contradictory results obtained by simple observation or controlling variables. Research in Science Education, 28(3), 365-376.

Piaget, J. \& Garcia, R. (1989). Psychogenesis and the history of science. New York: Columbia University Press.

Pines, A. L. \& West, L. H. T. (1986). Conceptual understanding and science learning: An interpretation of research with a source of knowledge framework. Science Education, 70 (5), 583-604.

Posner, G. J., Strike, K. A., Hewson, P. W. \& Gertzog, W. A. (1982). Accommodation of a scientific conception: Toward a theory of conceptual change. Science \& Education, 66 (2), 211-277.

Shepardson, D. P. \& Moje, E. B. (1999). The role of anomalous data in restructuring fourth graders' frameworks for understanding electric circuits. International Journal of Science Education, 21(1), 77-94.

Strike, K. A. \& Posner, G. J. (1992). A revisionist theory of conceptual change. In R. A. Duschl \& R. J. Hamilton (Eds.), Philosophy of science, cognitive psychology, and educational theory in practice (pp. 147-176). Albany: State University of New York Press.

Tsai, C.-C. (2000). Enhancing science instruction: The use of 'conflict maps'. International Journal of science education, 22(3), 285-302.

Tsai, C.-C. (2001). The interpretation construction design model for teaching science and its applications to Internet-based instruction in Taiwan. International Journal of Educational Development, 21, 401-415.

Tsai, C.-C. (2003). Using a conflict map as an instructional tool to change student alternative conceptions in simple series electric-circuits. International journal of science education, 25(3), 307-327.

Tsai, C.-C. (2005). Lasting effects of instruction guided by the conflict map: Experimental study of learning about the causes and the seasons. Journal of Research in Science Teaching, 42(10), 1089-1111.

Von Glasersfeld, E. (1989). Cognition, construction of knowledge, and teaching. Synthese, 80, 121-140.

West, L. H. T. \& Pines, A. L. (Eds.). (1985). Cognitive structure and conceptual change. Orlando: Academic.

Korea National University of Education

ChungBuk, the Republic of Korea

E-mail: jyoh3324@knue.ac.kr 